\title{
Emprego em serviços domésticos e acidentes de trabalho não fatais Housemaids and non-fatal occupational injuries
}

\author{
Vilma S Santana, Andréa M de Amorim, Roberval Oliveira, Shirlei Xavier, Jorge Iriart e \\ Liliane Belitardo
}

Instituto de Saúde Coletiva, Universidade Federal da Bahia (UFBA). Salvador, BA, Brasil

\section{Descritores \\ Acidentes de trabalho. Saúde ocupacional. Trabalho feminino. Trabalho. Saúde da mulher. Empregadas domésticas. Gênero.}

\section{Resumo}

\section{Objetivo}

Estimar a incidência anual de acidentes não fatais de acordo com variáveis sociodemográficas e ocupacionais entre empregadas em serviços domésticos.

\section{Métodos}

Inquérito de base comunitária conduzido com 1.650 mulheres de 10 a 65 anos de idade, que referiram ter atividade remunerada e que compunham uma amostra aleatória por conglomerados dos domicílios da cidade de Salvador, capital da Bahia. Os dados foram obtidos por meio de questionários individuais sobre condições de vida, trabalho e saúde. Foi utilizado o teste Exato de Fisher para diferenças de freqüências.

\section{Resultados}

Estimou-se a incidência anual de acidentes de trabalho não fatais em 5,0\%, maior entre as empregadas em serviços domésticos $(7,3 \%)$ do que entre as demais trabalhadoras $(4,5 \%)$, diferença estatisticamente significante $(p<0,05)$. Metade dos acidentes entre empregadas em atividades domésticas causou efeitos, freqüentemente não incapacitantes, mas que levaram $38,1 \%$ dessas mulheres a faltar ao trabalho.

Conclusões

Mulheres com emprego em atividades domésticas representam um contingente expressivo da força de trabalho e a alta incidência de acidentes ocupacionais não fatais entre elas revela sua importância em saúde pública, o que requer ações apropriadas de prevenção.

\section{Abstract}

Keywords

Accidents, occupational. Occupational health. Women, working. Work. Women's health. Housemaids. Gender.

\section{Objective}

To estimate the annual incidence of non-fatal work injuries according to sociodemographic and occupational variables among housemaids.

Methods

A community-based survey was conducted in a population of 1,650 women aged 10 to 65 years who reported a paid occupation randomly selected in a household sample of the city of Salvador, Brazil. Data was collected through individual questionnaires on living and work conditions and health status. Fisher Exact test was performed for frequency analysis.

Results

It was estimated an overall annual incidence of non-fatal work injuries in the study

Financiado pelo Conselho Nacional de Desenvolvimento Científico eTecnológico (CNPq - Processo n. 521226/98/8 Projeto Nordeste de Pesquisa); Secretaria de Planejamento do Estado da Bahia, Superintendência de Apoio ao Desenvolvimento Científico e Tecnológico (CADCT n. 68/2000).

Recebido em 7/11/2001. Reapresentado em 20/7/2002. Aprovado em 2/10/2002. 
population of $5.0 \%$, which was statistically significant $(p<0.05)$ higher among housemaids (7.3\%) than in the group with other occupations (4.5\%). Half of the injuries among housemaids were not related with long-term disabilities, and $38.1 \%$ women referred not being able to work for two weeks on average after the injury.

Conclusions

Housemaids represent a major contingent of the work force in Brazil and other Latin America countries. The high incidence of non-fatal work injuries in this working group reveals its public health relevance and the need for preventive programs.

\section{INTRODUÇÃO}

No Brasil, a ocupação mais comum entre as mulheres é o emprego em serviços domésticos, que representa cerca de $19,5 \%$ da participação feminina na força de trabalho. ${ }^{2}$ Em 1998, aproximadamente cinco milhões de mulheres tinham como atividade remunerada principal o serviço doméstico, ${ }^{9}$ o que demonstra a permanência em larga escala da delegação dos afazeres domésticos a terceiros, tal como ocorria na época colonial escravagista. A empregada para serviços domésticos é considerada imprescindível pela maior parte das famílias, sejam de áreas urbanas ou rurais, por permitir a redução da sobrecarga do trabalho de casa e a participação de mulheres, especialmente para as que têm filhos menores, no mercado de trabalho. Embora o emprego em atividades domésticas tenha sido abordado em vários estudos sociológicos $^{14}$ ou antropológicos, ${ }^{4,14,15}$ são poucas as pesquisas voltadas para a saúde dessas trabalhadoras. Exemplo disso são os acidentes de trabalho, um dos mais importantes problemas de saúde do trabalhador em todo o mundo, que permanecem pouco estudados, ${ }^{17}$ especialmente para empregadas em serviços domésticos. Um dos poucos estudos encontrados estimou uma incidência anual de 33,78/1.000 acidentes de trabalho não fatais entre diaristas, e de 41,11/1.000 em mensalistas. ${ }^{12}$ A falta de dados de morbidade em acidentes de trabalho para essas trabalhadoras dificulta a implantação de medidas de controle e prevenção.

No presente estudo, com base em dados coletados em um inquérito populacional realizado na cidade de Salvador, Bahia, Brasil, estima-se a incidência anual de acidentes ocupacionais não fatais em mulheres trabalhadoras, focalizando-se especificamente as empregadas em serviços domésticos. Estimativas de incidência de acordo com características sociodemográficas e ocupacionais são apresentadas,além dos aspectos descritivos dos acidentes de trabalho.

\section{MÉTODOS}

Entre agosto e dezembro de 2000, realizou-se um amplo estudo de base comunitária na cidade de Salvador, no qual todos os indivíduos com idade entre 10 e 65 anos, de 2.513 famílias aleatoriamente selecionadas, responderam a questionários individuais sobre condições de vida, trabalho e saúde. Identificaram-se 5.205 pessoas nessa faixa de idade, entre as quais selecionou-se a população deste estudo, restrita a mulheres que referiram ter pelo menos um trabalho remunerado. A amostragem foi do tipo aleatória de superfície, realizada por meio de sorteio de sub-áreas de um mapa aerofotográfico de toda a área urbana da cidade. Essas sub-áreas continham uma média de 90 domicílios. Considerando-se o número médio de pessoas na faixa de idade de interesse estimado pelo Censo, foi possível definir o número de sub-áreas necessárias para se alcançar o tamanho definido para a amostra.

Equipes treinadas realizaram a coleta de dados por meio de entrevistas individuais, após o levantamento de todas as famílias residentes em cada sub-área, e o cadastramento de todos os seus membros. Questionários foram aplicados individualmente para se obter dados sociodemográficos, ocupacionais e de saúde, onde se incluía a ocorrência de acidentes em geral. Em caso positivo, ao acidentado era aplicado um questionário específico onde eram detalhadas as características do evento com uma pequena narrativa, utilizando-se as próprias palavras do entrevistado. Quando o acidente era identificado como ocupacional, outras perguntas sobre aspectos clínicos e sociais eram realizadas. Assim, nenhuma pergunta direta sobre acidente de trabalho era formulada, por se presumir que trabalhadores do setor informal ou sem carteira de trabalho não estariam conscientes da natureza ocupacional do agravo, pela falta de cobertura previdenciária ou de seguro acidente de traba1ho. Para todas as empregadas em atividades domésticas, coletaram-se dados sobre as condições de trabalho. Para garantir a fidedignidade das informações, supervisores distribuídos nas sub-áreas realizavam reentrevistas parciais em sub-amostras da população. Em um estudo-piloto, a viabilidade de uso dos instrumentos de pesquisa e da estratégia operacional foi testada e realizados os ajustes necessários. Os instru- 
mentos da pesquisa foram elaborados pela equipe, baseando-se em questionários desenvolvidos por Fachini et al $^{6}$ (1998) e Moraes \& Barata $^{12}$ (1998).

Considerou-se como acidentes de trabalho "qualquer dano infligido ao corpo por transferência de energia durante o trabalho (típico), ou no deslocamento até o local do trabalho (trajeto) que envolvesse uma curta duração entre exposição e efeitos identificáveis após a ocorrência do evento/circunstância". ${ }^{10}$ Quando havia referência a mais de um acidente no período de um ano, definido para o estudo, apenas o mais recente foi considerado. As variáveis selecionadas foram idade, situação conjugal, cor da pele de acordo com a observação do entrevistador, nível de escolaridade, nível socioeconômico, definido com base no número de aparelhos eletrodomésticos e outros bens (baixo, menos de 2 itens; médio, de 3 a 5 itens; e alto, acima de 5 itens) e dupla jornada de trabalho caracterizada como sim, quando acumulava atividade remunerada e trabalho doméstico para suas próprias famílias, e não, quando desenvolvia apenas atividade remunerada. As características das condições de trabalho das empregadas em serviços domésticos foram "se residia com os patrões", duração da jornada diária e semanal, ajuda no trabalho, "se trabalhava para mais de uma família", "se havia recebido treinamento", ou "se tinha carteira de trabalho assinada", e em caso negativo qual o motivo. Satisfação com a profissão e se desejaria mudar para uma outra ocupação também foram objeto de perguntas. Para caracterizar os acidentes de trabalho, selecionaram-se as seguintes variáveis: local onde ocorreu, causa percebida, o tipo de lesão, efeitos do acidente sobre a capacidade de trabalho referidos pela entrevistada, e que foi classificada como: 1) sem efeito permanente, completa recuperação da capacidade funcional e integridade física e psicológica após o acidente; 2) com efeito permanente, possibilitando trabalhar na mesma atividade; 3) com efeito permanente e com capacidade apenas para exercer outro tipo de atividades; 4) efeito permanente com incapacidade para o trabalho. Além dessas, consideraram-se o número de dias de afastamento de trabalho em conseqüência do acidente, se continuou recebendo o salário e se o acidente poderia ter sido evitado.

O protocolo da pesquisa foi submetido e aprovado pela Comissão de Ética em Pesquisa do Hospital Prof. Edgard Santos da Universidade Federal da Bahia. Todos os indivíduos forneceram consentimento escrito após esclarecimento dos propósitos da investigação. Os dados foram duplamente digitados por pessoas diferentes, utilizando-se o Epi-Info 6.0, e as bases de dados checadas e corrigidas para inconsistências. A incidência anual foi calculada dividindo-se o número de casos identificados de acidentes de trabalho, no período de referência, pelo total da população sob risco. Note-se que embora o estudo seja transversal, acidentes são eventos agudos e circunscritos no tempo, podendo-se considerá-los casos incidentes, ainda que baseando-se em informações referidas. As estimativas de incidência ajustadas para o desenho amostral foram calculadas empregando-se a rotina Surveymeans, SAS Versão 8.11. Foi usado o Teste Exato de Fisher para diferenças de frequências.

\section{RESULTADOS}

Dass 5.205 pessoas entrevistadas individualmente da amostra original, consideraram-se apenas as de sexo feminino, com idade entre 10 e 65 anos, e que exerciam alguma atividade remunerada $(n=1.721)$. Destas, 71 não responderam aos questionários individuais, ficando a população do estudo composta por 1.650 mulheres, das quais $18,4 \%(n=303)$ eram empregadas em serviços domésticos e 1.347 (81,6\%) referiram outras ocupações.

De acordo com a Tabela 1, verifica-se que trabalhadoras em serviços domésticos eram mais jovens, apresentavam maior freqüência de mulheres solteiras, de cor negra, de baixo nível socioeconômico e baixa escolaridade do que o grupo referente. Empregadas em serviços domésticos se engajavam menos freqüentemente em atividades domésticas não remuneradas para a própria familia do que as que tinham outras ocupações. Todas essas diferenças foram estatisticamente significantes $(\mathrm{p}<0,001)$. Entre as empregadas em serviços domésticos, a proporção de meninas e adolescentes de 10 a 14 anos $(1,7 \%)$ foi 3,4 vezes maior do que a estimada $(0,5 \%)$ entre as empregadas em outra ocupação. Resultados semelhantes também foram encontrados para as faixas de 15 a 17 anos e de 18 a 20 anos, com proporções 1,6 e 2,2 vezes maiores, respectivamente. Esses diferenciais praticamente desaparecem entre as mulheres acima de 20 anos.

$\mathrm{Na}$ Tabela 2, apresentam-se dados descritivos ocupacionais do grupo de empregadas em serviços domésticos. Observa-se que apenas 31,6\% residiam nas casas dos patrões, mas apesar disso a maioria trabalhava mais de 8 horas por dia $(51,3 \%)$, e mais do que 5 dias por semana $(64,0 \%)$, não contando com ajuda no trabalho $(67,8 \%)$. Complementação de renda era buscada no trabalho em outras residências por 19,3\% destas trabalhadoras. Quanto à profissionalização, verifica-se que apenas $6,7 \%$ referiram ter recebido algum tipo de treinamento para o trabalho. A grande maioria (70,5\%) não tinha carteira de trabalho assinada. Essa freqüência foi mais elevada do que 
a encontrada entre as trabalhadoras com outras ocupações $(54,4 \%)$, diferença estatisticamente significante $(\mathrm{p}<0,005)$, dados não apresentados. Entre as empregadas em serviços domésticos que não tinham carteira de trabalho, a razão mais freqüentemente alegada para isso foi que "o patrão não quis assinar a carteira" $(37,1 \%)$, e de que este "é um emprego temporário" (19,2\%). Vale notar que 3,8\% referiram recusar o registro na carteira de trabalho "para evitar a identificação da ocupação como empregada doméstica". Quanto à satisfação com a ocupação, verifica-se que embora $57,0 \%$ tenham declarado estar satisfeitas com o trabalho, 78,1\% gostariam de trocar de profissão.

A incidência de acidentes de trabalho não fatais está mostrada nas Tabelas 3 e 4 . Pode-se observar que a incidência anual de acidentes de trabalho não fatais foi estimada em 5,0\% (Tabela 3), maior entre as trabalhadoras domésticas $(7,3 \%)$ do que entre aquelas que referiram outro tipo de ocupação $(4,5 \%)$, diferença estatisticamente significante $(p<0,05)$. Ainda

Tabela 1 - Características sociodemográficas da população do estudo de acordo com a ocupação principal.

\begin{tabular}{|c|c|c|c|c|c|c|}
\hline \multirow[t]{3}{*}{ Variáveis } & \multicolumn{4}{|c|}{ Ocupação principal } & \multirow{2}{*}{\multicolumn{2}{|c|}{ Total }} \\
\hline & \multicolumn{2}{|c|}{ Emprego doméstico } & \multicolumn{2}{|c|}{ Outro trabalho } & & \\
\hline & $N=303$ & $18,4 \%$ & $\mathrm{~N}=1.347$ & $81,6 \%$ & $N=1.650$ & $100,0 \%$ \\
\hline \multicolumn{7}{|l|}{ Idade em anos*** } \\
\hline $10-14$ & 5 & 1,7 & 6 & 0,5 & 11 & 0,7 \\
\hline $15-17$ & 12 & 4,0 & 33 & 2,5 & 45 & 2,7 \\
\hline $18-20$ & 43 & 14,2 & 86 & 6,4 & 129 & 7,8 \\
\hline $21-34$ & 118 & 38,9 & 557 & 41,4 & 675 & 41,0 \\
\hline $35-65$ & 125 & 41,2 & 663 & 49,3 & 788 & 47,8 \\
\hline \multicolumn{7}{|l|}{ Situação conjugal*** } \\
\hline Solteira & 167 & 56,1 & 574 & 43,0 & 741 & 45,3 \\
\hline Casada/consensual & 102 & 34,2 & 583 & 43,6 & 685 & 42,0 \\
\hline Viúva/divorciada & 29 & 9,7 & 179 & 13,4 & 208 & 12,7 \\
\hline \multicolumn{7}{|l|}{ Cor da pele e $^{* * *}$} \\
\hline Negra & 217 & 71,6 & 776 & 57,6 & 993 & 60,2 \\
\hline \multirow{2}{*}{\multicolumn{7}{|c|}{ Nível de Escolaridade*** }} \\
\hline & & & & & & \\
\hline Analfabeto & 45 & 14,9 & 42 & 3,1 & 87 & 5,3 \\
\hline $1^{\circ}$ grau & 209 & 69,2 & 409 & 30,4 & 618 & 37,5 \\
\hline $2^{\circ}$ grau & 48 & 15,9 & 729 & 54,1 & 777 & 47,1 \\
\hline Superior & - & - & 167 & 12,4 & 167 & 10,1 \\
\hline \multicolumn{7}{|c|}{ Nível socioeconômico*** } \\
\hline Baixo & 257 & 84,8 & 540 & 40,1 & 797 & 48,4 \\
\hline Médio & 31 & 10,2 & 488 & 36,3 & 519 & 31,5 \\
\hline Alto & 15 & 5,0 & 317 & 23,6 & 332 & 20,1 \\
\hline \multicolumn{7}{|l|}{ Dupla jornada*** } \\
\hline Sim & 160 & 52,8 & 874 & 64,9 & 1.034 & 62,7 \\
\hline Não & 143 & 47,2 & 473 & 35,1 & 616 & 37,3 \\
\hline
\end{tabular}

Tabela 2 - Características do trabalho das empregadas em serviços domésticos ( $N=303)$.

\begin{tabular}{|c|c|c|}
\hline Variáveis & $\mathrm{N}$ & $\%$ \\
\hline Mora na casa dos patrões $(\mathrm{N}=301)$ & 95 & 31,6 \\
\hline \multicolumn{3}{|l|}{ Horas diárias de trabalho $(\mathrm{N}=302)$} \\
\hline Até $8 \mathrm{~h}$ & 147 & 48,7 \\
\hline$>8 \mathrm{~h}$ & 155 & 51,3 \\
\hline \multicolumn{3}{|l|}{ Número de dias que trabalha por semana $(\mathrm{N}=302)$} \\
\hline 1 a 5 & 109 & 36,1 \\
\hline 6 & 134 & 44,4 \\
\hline 7 & 59 & 19,5 \\
\hline \multicolumn{3}{|l|}{ Com quem divide o trabalho $(\mathrm{N}=301)$} \\
\hline Patroa ou alguém da família da patroa & 42 & 14,0 \\
\hline Outra empregada & 39 & 13,0 \\
\hline Outros & 16 & 5,3 \\
\hline Ninguém & 204 & 67,7 \\
\hline Trabalha para outra casa $(N=301)$ & 58 & 19,3 \\
\hline Recebeu treinamento $(N=299)$ & 20 & 6,7 \\
\hline Não tem carteira assinada $(\mathrm{N}=291)$ & 205 & 70,5 \\
\hline \multicolumn{3}{|l|}{ Motivo referido para não ter carteira assinada $(\mathrm{N}=213)$} \\
\hline O emprego é passageiro & 41 & 19,2 \\
\hline O patrão não quis & 79 & 37,1 \\
\hline Não tem documentos ou carteira de trabalho & 11 & 5,2 \\
\hline Ainda não tinha pensado nisto & 12 & 5,6 \\
\hline Para não pagar INSS & 1 & 0,5 \\
\hline Não quer o registro de empregada doméstica na carteira & 8 & 3,8 \\
\hline Outros & 61 & 28,6 \\
\hline Satisfeita com o trabalho $(\mathrm{N}=302)$ & 172 & 57,0 \\
\hline Gostaria de trocar de ocupação $(N=297)$ & 232 & 78,1 \\
\hline
\end{tabular}

$\mathrm{N}=$ Número de pessoas da amostra; $(\mathrm{N})$ = número de pessoas com dados disponíveis. 
Tabela 3 - Incidência anual de acidentes de trabalho não fatais, de acordo com características sociodemográficas da população.

\begin{tabular}{|c|c|c|c|c|c|c|c|c|c|}
\hline \multirow{3}{*}{ Variáveis } & \multicolumn{6}{|c|}{ Ocupação principal } & \multirow{2}{*}{\multicolumn{3}{|c|}{ Total $(\mathrm{N}=1.650)$}} \\
\hline & \multicolumn{3}{|c|}{ Emprego doméstico } & \multicolumn{3}{|c|}{ Outro trabalho } & & & \\
\hline & $N=303$ & $\mathrm{n}=22$ & $\mathrm{I}=7,3 \% * *$ & $\mathrm{~N}=1.347$ & $\mathrm{n}=61$ & $\mathrm{I}=4,5 \% * *$ & \multicolumn{2}{|c|}{$\begin{array}{c}\text { Total }(\mathrm{N}=1 \\
650 \quad \mathrm{n}=83\end{array}$} & $\mathrm{I}=5,0 \%$ \\
\hline \multicolumn{10}{|l|}{ Idade em anos } \\
\hline $10-14$ & 5 & 0 & - & 6 & 0 & - & 11 & 0 & - \\
\hline $15-17$ & 12 & 3 & 25,0 & 33 & 2 & 6,1 & 45 & 5 & 11,4 \\
\hline $18-20$ & 43 & 4 & 9,3 & 86 & 2 & 2,4 & 129 & 6 & 6,3 \\
\hline $21-34$ & 118 & 8 & 6,8 & 557 & 28 & 5,0 & 675 & 36 & 5,3 \\
\hline $35-65$ & 125 & 7 & 5,6 & 663 & 29 & 4,4 & 788 & 36 & 4,5 \\
\hline \multicolumn{10}{|l|}{ Situação conjugal } \\
\hline Solteira & 167 & 14 & 8,4 & 574 & 23 & 4,0 & 741 & 37 & 5,0 \\
\hline Casada/consensual & 102 & 6 & 5,9 & 583 & 32 & 5,5 & 685 & 38 & 5,9 \\
\hline Viúva/divorciada & 29 & 2 & 6,9 & 179 & 6 & 3,4 & 208 & 8 & 3,8 \\
\hline \multicolumn{10}{|l|}{ Cor da pele } \\
\hline Negra & 217 & 18 & 8,3 & 776 & 44 & $* * 5,7$ & 993 & 62 & $* * * 6,2$ \\
\hline Não negra & 86 & 4 & 4,7 & 571 & 17 & 3,0 & 657 & 21 & 3,2 \\
\hline \multicolumn{10}{|l|}{ Nível de escolaridade } \\
\hline Analfabeto & 45 & 2 & 4,4 & 42 & 3 & 7,1 & 87 & 5 & 6,0 \\
\hline $1^{\circ}$ grau & 209 & 16 & 7,7 & 409 & 21 & 5,1 & 618 & 37 & 6,6 \\
\hline $2^{\circ}$ grau & 48 & 4 & 8,3 & 729 & 33 & 4,5 & 777 & 37 & 4,8 \\
\hline Superior & - & 0 & - & 167 & 4 & 2,4 & 167 & 4 & 2,4 \\
\hline \multicolumn{10}{|l|}{ Nível socioeconômico } \\
\hline Baixo & 257 & 20 & 7,8 & 540 & 25 & 4,6 & 797 & 45 & 5,6 \\
\hline Médio & 31 & 2 & 6,5 & 488 & 25 & 5,1 & 519 & 27 & 5,2 \\
\hline Alto & 15 & 0 & - & 317 & 11 & 3,5 & 332 & 11 & 3,3 \\
\hline \multicolumn{10}{|l|}{ Dupla jornada } \\
\hline Sim & 160 & 12 & 7,5 & 874 & 45 & $* 5,2$ & 616 & 26 & 4,2 \\
\hline Não & 143 & 10 & 7,0 & 473 & 16 & 3,4 & 1.034 & 57 & 5,5 \\
\hline
\end{tabular}

$\mathrm{N}=$ número de pessoas da amostra; $\mathrm{n}=$ número de casos de acidentes de trabalho não fatais.

I= incidência anual de acidentes de trabalho não fatais.

Teste Exato de Fisher: ${ }^{*} p<0,10,{ }^{* *} p<0,05,{ }^{* * *} p<0,0001$.

na Tabela 3, pode ser visto que houve casos de acidente na faixa de 10 a 14 anos de idade nos dois grupos ocupacionais. Em ambos, percebe-se uma discreta tendência de diminuição da incidência com a idade, mas os números são muito pequenos, especialmente entre as mulheres empregadas em serviços domésticos, o que pode ter determinado a alta incidência de $25 \%$ estimada nas meninas de 15 a 17 anos. Nenhuma dessas diferenças foi estatisticamente significante. A principal variação na incidência de acordo com as variáveis sociodemográficas ocorreu com a cor da pele, mas apenas entre as empregadas em ocupações não domésticas: especificamente, mulheres negras obtiveram mais altas incidências de acidentes de trabalho $(6,2 \%)$ do que as não negras $(3,2 \%)$, diferença estatisticamente significante $(\mathrm{p}<0,0001)$. Não se encontraram diferenças marcantes na incidência dos acidentes de trabalho em relação ao nível de escolaridade e socioeconômico. Todavia, a incidência de acidentes foi maior entre as mulheres com dupla jornada, apenas na categoria que referia ocupação remunerada não doméstica $(p<0,10)$.

Com relação à distribuição dos acidentes no grupo de trabalhadoras em serviços domésticos (Tabela 4), verifica-se que a incidência aumentou com a jornada de trabalho, chegando a quase três vezes a diferença entre as mulheres que trabalhavam todos os dias da semana em comparação com as que folgavam aos sábados e domingos $(10,2 \% / 3,7 \%)$. Resultados semelhantes foram encontrados para a jornada diária de trabalho $(11,0 \% / 3,4 \%, \mathrm{p}<0,0001)$. Embora tenha se registrado maior incidência de acidentes entre as trabalhadoras em atividades domésticas sem carteira, quando comparadas com as que tinham carteira, essa diferença não foi estatisticamente significante.

Tabela 4 - Incidência anual de acidentes de trabalho não fatais de acordo com as características ocupacionais das empregadas em serviços domésticos.

\begin{tabular}{|c|c|c|c|}
\hline Variáveis & $N=303^{*}$ & $\mathrm{n}=22$ & $\begin{array}{l}\text { Incidência } \\
\text { anual (\%) }\end{array}$ \\
\hline \multicolumn{4}{|c|}{ Mora na casa dos patrões } \\
\hline Sim & 95 & 6 & 6,3 \\
\hline Não & 206 & 16 & 7,8 \\
\hline \multicolumn{4}{|c|}{ Duração da jornada diária de trabalho*** } \\
\hline Até $8 \mathrm{~h}$ & 147 & 5 & 3,4 \\
\hline Mais de $8 \mathrm{~h}$ & 155 & 17 & 11,0 \\
\hline \multicolumn{4}{|c|}{ Número de dias de trabalho por semana } \\
\hline 1 a 5 & 109 & 4 & 3,7 \\
\hline 6 & 134 & 12 & 9,0 \\
\hline 7 & 59 & 6 & 10,2 \\
\hline \multicolumn{4}{|c|}{ Trabalha para outra casa } \\
\hline Sim & 58 & 5 & 8,6 \\
\hline Não & 243 & 17 & 7,0 \\
\hline \multicolumn{4}{|c|}{ Recebeu treinamento } \\
\hline Sim & 20 & 3 & 15,0 \\
\hline Não & 279 & 19 & 6,8 \\
\hline \multicolumn{4}{|c|}{ Carteira assinada } \\
\hline Sim & 86 & 5 & 5,8 \\
\hline \multirow{2}{*}{\multicolumn{4}{|c|}{ Satisfação com o trabalho }} \\
\hline & & & \\
\hline Sim & 172 & 11 & 6,4 \\
\hline Não & 125 & 11 & 8,8 \\
\hline \multicolumn{4}{|c|}{ Trocaria de profissão } \\
\hline Sim & 232 & 18 & 7,8 \\
\hline Não & 65 & 4 & 6,2 \\
\hline
\end{tabular}

*Subtotais diferem devido a dados não disponíveis.

$\mathrm{N}=$ número de pessoas da amostra.

$\mathrm{n}=$ número de casos de acidentes de trabalho não fatais. Teste Exato de Fisher: ${ }^{* * *} p<0,0001$. 
Na Tabela 5, apresentam-se dados apenas para mulheres acidentadas no trabalho. No geral, os acidentes de trabalho ocorreram com maior freqüência na própria casa da vítima, durante a realização de atividades para a família $(32,5 \%)$, seguindo-se pela "firma", "casa do patrão" e trajeto para o trabalho. Especificamente, entre as empregadas em serviços domésticos, a maioria dos acidentes de trabalho aconteceu na casa do patrão $(63,6 \%)$, seguida por acidentes na própria casa $(18,2 \%)$, e no trajeto $(18,2 \%)$. No grupo de mulheres com ocupação não doméstica, a maioria dos acidentes ocorreu na própria casa $(37,7 \%)$, durante os afazeres domésticos, sendo que em $2^{\circ}$ lugar se encontravam os acidentes típicos de trabalho ocorridos em firmas $(27,9 \%)$, acidentes de trajeto $(14,7 \%)$, e por último os acidentes de trabalho típicos ocorridos em via pública (11,5\%). Em ambos os grupos, as quedas foram a principal causa de acidentes de trabalho, responsável por $41,5 \%$. Entre as trabalhadoras em serviços domésticos chegou a 52,6\%, maior do que entre as mulheres com outras ocupações (37,0\%). Em geral, o tipo de lesão mais comum entre as acidentadas foi a laceração, referida por $22,5 \%$ seguida pela queimadura (19,7\% dos casos). As queimaduras foram mais comuns entre as empregadas em atividades domésticas $(33,3 \%)$ do que entre as trabalhadoras de outras ocupações $(15,1 \%)$. Entre as que tinham outras ocupações, as lacerações prevaleceram.

Ainda na Tabela 5, observam-se dados sobre a gravidade do acidente, analisada pelos seus efeitos referidos. Verifica-se que a maioria dos acidentes não causou efeito permanente (80,3\%). Chegou a $19,1 \%$ a proporção de acidentes que deixou efeitos permanentes entre as empregadas em serviços domésticos, semelhante à estimada no grupo de trabalhadoras com outro tipo de ocupação $(20 \%)$. Houve um caso de seqüela incapacitante para qualquer tipo de trabalho entre as empregadas em atividades domésticas, e um com incapacidade para realizar o mesmo tipo de trabalho entre as demais trabalhadoras. Cerca de $43,4 \%$ das acidentadas tiveram de faltar ao trabalho devido ao acidente, com maior proporção entre as trabalhadoras em atividades não domésticas (44,3\%) do que entre as empregadas em serviços domésticos $(40,9 \%)$, diferença não estatisticamente significante. A maioria referiu que os acidentes poderiam ser evitados $(68,9 \%)$, tanto entre as empregadas em serviços do-

Tabela 5 - Características dos acidentes de trabalho não fatais de acordo com o tipo de ocupação principal.

\begin{tabular}{|c|c|c|c|c|c|c|}
\hline \multirow{3}{*}{ Variáveis } & \multicolumn{4}{|c|}{ Ocupação principal } & \multirow{2}{*}{\multicolumn{2}{|c|}{$\begin{array}{c}\text { Total } \\
(\mathrm{N}=1.650)\end{array}$}} \\
\hline & \multicolumn{2}{|c|}{$\begin{array}{l}\text { Emprego doméstico } \\
(\mathrm{N}=303)\end{array}$} & \multicolumn{2}{|c|}{$\begin{array}{l}\text { Outro trabalho } \\
(\mathrm{N}=1.347)\end{array}$} & & \\
\hline & $\mathrm{n}=22$ & $26,5 \%$ & $\mathrm{n}=61$ & $73,5 \%$ & $\mathrm{n}=83$ & $100,0 \%$ \\
\hline \multicolumn{7}{|l|}{ Local do acidente $e^{* * *}$} \\
\hline Casa do patrão & 14 & 63,6 & 2 & 3,3 & 16 & 19,3 \\
\hline Na própria casa trabalhando para a família & 4 & 18,2 & 23 & 37,7 & 27 & 32,5 \\
\hline Estabelecimento ou empresa & 0 & - & 17 & 27,9 & 17 & 20,5 \\
\hline Via pública (trabalhando) & 0 & - & 7 & 11,5 & 7 & 8,4 \\
\hline Trajeto para o trabalho & 4 & 18,2 & 9 & 14,7 & 13 & 15,7 \\
\hline Outros & 0 & - & 3 & 4,9 & 3 & 3,6 \\
\hline \multicolumn{7}{|l|}{ Causa do acidente } \\
\hline Queda & 10 & 52,6 & 17 & 37,0 & 27 & 41,5 \\
\hline Contato com substâncias quentes & 4 & 21,1 & 8 & 17,4 & 12 & 18,5 \\
\hline Manejo de instrumentos pérfuro-cortantes & 3 & 15,8 & 12 & 26,1 & 15 & 23,0 \\
\hline Contato com superfícies aquecidas/muito frias & 2 & 10,5 & 2 & 4,3 & 4 & 6,2 \\
\hline Outros & - & - & 7 & 15,2 & 7 & 10,8 \\
\hline \multicolumn{7}{|l|}{ Tipo da lesão principal } \\
\hline Queimadura & 6 & 33,3 & 8 & 15,1 & 14 & 19,7 \\
\hline Laceração & 3 & 16,7 & 13 & 24,5 & 16 & 22,5 \\
\hline Hematoma & 3 & 16,7 & 4 & 7,6 & 7 & 9,9 \\
\hline Perfuração & 1 & 5,6 & 4 & 7,6 & 5 & 7,0 \\
\hline Estiramento & 2 & 11,1 & 6 & 11,3 & 8 & 11,3 \\
\hline Luxação & 1 & 5,6 & 6 & 11,3 & 7 & 9,9 \\
\hline Fratura & 1 & 5,6 & 3 & 5,6 & 4 & 5,6 \\
\hline Outro & 1 & 5,6 & 9 & 17,0 & 10 & 14,1 \\
\hline \multicolumn{7}{|l|}{ Efeitos referidos do acidente } \\
\hline Sem efeito permanente & 17 & 81,0 & 48 & 80,3 & 65 & 80,3 \\
\hline \multicolumn{7}{|l|}{ Com efeito permanente } \\
\hline Sem incapacidade para o trabalho na mesma ativ & de 3 & 14,3 & 11 & 18,3 & 14 & 17,3 \\
\hline Com incapacidade para o trabalho na mesma ativ & ade - & - & 1 & 1,7 & 1 & 1,2 \\
\hline Com incapacidade para qualquer tipo de trabalho & 1 & 4,8 & - & - & 1 & 1,2 \\
\hline \multicolumn{7}{|l|}{ Número de dias de afastamento do trabalho } \\
\hline Sem afastamento & 13 & 59,1 & 34 & 55,7 & 47 & 56,6 \\
\hline Até duas semanas & 5 & 22,7 & 18 & 29,5 & 23 & 27,7 \\
\hline Mais de duas semanas & 4 & 18,2 & 9 & 14,8 & 13 & 15,7 \\
\hline Recebeu salário durante o afastamento & 5 & 55,6 & 13 & 48,2 & 18 & 50,0 \\
\hline \multicolumn{7}{|l|}{ Acidente poderia ser evitado } \\
\hline Sim & 11 & 61,1 & 40 & 71,4 & 51 & 68,9 \\
\hline Não & 7 & 38,9 & 16 & 28,6 & 23 & 31,1 \\
\hline
\end{tabular}

$\mathrm{N}=$ número de pessoas da amostra; $\mathrm{n}=$ número de casos de acidentes.

Teste Exato de Fisher: $* * * p<0,0001$ 
mésticos $(61,1 \%)$, quanto entre as demais trabalhadoras $(71,4 \%)$.

\section{DISCUSSÃO}

Os resultados do estudo evidenciam que a incidência anual de acidentes de trabalho não fatais entre mulheres que exercem atividades remuneradas é de $5 \%$, e que a ocupação em serviços domésticos proporciona um risco maior do que as demais, com diferença estatisticamente significante $(p<0,05)$. Entre as empregadas domésticas, observou-se que esse risco aumenta com o tempo de trabalho, medido pela duração da jornada diária ou semanal, e que embora grande parte dos acidentes não tenha tido severidade suficiente para produzir incapacidade permanente, levou ao afastamento das atividades por cerca de duas $(22,7 \%)$ ou mais semanas (18,2\%). Ainda neste grupo de trabalhadoras, nota-se também que a maioria dos casos ocorreu na casa do patrão e foi causada principalmente por quedas $(52,6 \%)$ e contato com substâncias em altas temperaturas, sendo as lesões mais comuns do que as queimaduras. A gravidade desses acidentes revela-se no fato de que embora $81 \%$ não tenham deixado efeito permanente, $22,7 \%$ motivaram o afastamento do trabalho por duas semanas, e 18,2\% por mais de duas semanas. Entre as empregadas em ocupações não domésticas, verifica-se que a incidência foi maior entre as de cor negra $(p<0,05)$ e que o acidente ocorreu mais comumente quando se encontravam em sua própria casa, ao realizar trabalhos domésticos para a família $(37,7 \%)$, seguido pela empresa $(27,9 \%)$ e pelo trajeto para o trabalho $(14,7 \%)$. Também neste grupo foram mais comuns as quedas $\mathrm{e}$ as lesões não incapacitantes, embora acidentes tenham causado a falta ao trabalho por longos períodos de tempo.

Esses dados revelam não apenas que mulheres se acidentam no trabalho em freqüência elevada, mas também que é apenas aparente a segurança do emprego em serviços domésticos, que apresenta risco mais elevado do que as demais ocupações. Entre os poucos estudos que referem acidentes de trabalho entre empregados em ocupações domésticas, destaca-se o trabalho de Moraes \& Barata $^{12}$ (1998) realizado no Estado de São Paulo, com uma amostra populacional de 30.000 pessoas, que estimou uma taxa anual de acidentes de trabalho de 33,78/1.000 entre empregados domésticos mensalistas, e de 41,11/1.000 entre diaristas, estimativas próximas às encontradas no presente estudo. Em uma outra investigação, estimou-se que empregadas domésticas representavam cerca de $7,1 \%$ dos casos de acidentes de trabalho, identificados entre os agravos por causas externas atendidos em Serviços de Emergência da cidade do Salvador,
Bahia. ${ }^{5}$ Como se avalia que existam aproximadamente 5.028.469 de empregadas domésticas no País, ${ }^{9}$ pode-se supor que 351.993 casos de acidentes de trabalho aconteçam a cada ano nesta categoria de trabalhadoras. Trata-se, portanto, de um problema de saúde pública que não pode permanecer ignorado pelos custos sociais e econômicos, diretos e indiretos a ele relacionados. No entanto, é flagrante a invisibilidade do trabalho das empregadas domésticas nos estudos de saúde ocupacional e nas políticas de saúde do trabalhador, em que pesem os avanços no seu reconhecimento profissional e conquista de direitos trabalhistas, especialmente benefícios sociais. Permanece a falta de mecanismos de segurança, proteção à saúde e prevenção de doenças e agravos ocupacionais. Isto não surpreende, considerando-se as origens históricas do emprego doméstico demarcadas pelo trabalho dos escravos no Brasil Colonial, no qual a posse do corpo do trabalhador por parte do "senhor" não lhe conferia responsabilidade ou obrigação com o cuidado à saúde ou prevenção de problemas de saúde dos seus subordinados.

Apesar da reconhecida importância dos acidentes de trabalho para a saúde pública em todo o mundo, no Brasil ainda são poucos os dados disponíveis sobre a mortalidade ou morbidade por acidentes ocupacionais que apresentem qualidade aceitável e abranjam todos os trabalhadores. Por isso são comumente despercebidos como problema de saúde por parte das autoridades, o que talvez em parte justifique a pouca importância que tem sido dada a este problema no País. Além da subenumeração dos acidentes de trabalho devido a problemas de reconhecimento e registro, estatísticas sobre eles no Brasil são parciais por se restringirem aos trabalhadores com contrato formal. Isto porque a principal fonte de registro, a CAT, tem propósitos mais administrativos do que de vigilância epidemiológica, sendo empregada prioritariamente para o sistema de seguridade social. Portanto não abrangem os trabalhadores do setor informal da economia, como também aqueles que não dispõem de registro oficial de contrato do trabalho, que compõem a maioria das mulheres que desempenham atividades em serviços domésticos, conforme mostrado no presente estudo. Esta invisibilidade da morbidade ocupacional das atividades domésticas sustenta-se na concepção de que entre elas os acidentes de trabalho seriam "naturais", posto que as residências dos patrões, local onde comumente acontecem, não são vistas na perspectiva dos ambientes laborais onde tradicionalmente se recorta o cuidado com os riscos ocupacionais e os efeitos sobre a saúde, como na indústria. Essas condições de risco precisam ser reconhecidas, especialmente porque são passíveis de medidas de pre- 
venção como todos os acidentes de trabalho.

Além da maior incidência dos acidentes de trabalho entre as trabalhadoras de ocupações domésticas, um outro achado importante do estudo foi o aumento da incidência dos acidentes de trabalho não fatais com a jornada de trabalho, compreensível pelo aumento do tempo de exposição ao risco de acidentes. Ressalta-se desses dados a grande diferença da incidência de acordo com a jornada, sugestiva da importância da fadiga e da falta de tempo para o descanso para a ocorrência de acidentes, fundamentais na formulação de estratégias de prevenção entre essas trabalhadoras. Resultados semelhantes foram encontrados em área rural ${ }^{7} \mathrm{e}$ área urbana ${ }^{12}$ no Brasil. Distintamente dos achados de outros estudos sobre trabalhadores de outras ocupações, a incidência de acidentes de trabalho não foi maior entre as trabalhadoras com baixo nível de escolaridade ou socioeconômico, possivelmente devido à grande homogeneidade do grupo de trabalhadoras em serviços domésticos em relação à essas características. Surpreende o diferencial relativo à cor da pele encontrado para as mulheres com trabalho não doméstico, nos quais mulheres de cor negra têm um risco duas vezes maior do que as não negras $(p<0,05)$. Possivelmente isto reflete a maior concentração de mulheres negras em atividades menos seguras do que as não negras, o que merece uma análise mais detalhada, pois pode ser resultante de discriminação racial no acesso a postos de trabalho menos seguros. Embora mulheres de cor negra empregadas em serviços domésticos tivessem maior incidência de acidentes de trabalho do que as não negras, esta diferença não foi estatisticamente significante, sendo que estudos com amostras maiores podem produzir dados mais conclusivos.

Quanto às características dos acidentes de trabalho, os dados revelam diferenças do local e tipo de lesão de acordo com o a ocupação exercida, explicadas pelas peculiaridades das atividades e local de trabalho desses grupos. É importante considerar a grande ocorrência de acidentes de trabalho entre as mulheres quando realizavam atividades domésticas para a própria família, maior entre as que trabalhavam em ocupação não doméstica. Isto confima os achados de estudos que mostraram ser o ambiente doméstico, independente de ser um espaço de trabalho remunerado, fonte de muitos riscos para traumas, ${ }^{3,11}$ mas nenhuma relação entre acidentes de trabalho com o emprego doméstico foi referida. Isto pode ser devido ao fato da maioria dos estudos ser de países onde empregadas domésticas são minoria, e o trabalho doméstico seja realizado principalmente pelos próprios membros do grupo familiar.
Houve maior freqüência de seqüelas dos acidentes entre as empregadas em serviços domésticos, embora as diferenças desapareçam ao se considerar o afastamento imediato do trabalho em conseqüência dos acidentes. Isto indica que acidentes de trabalho no grupo de empregadas em serviços domésticos estão produzindo mais freqüentemente efeitos permanentes, e que ainda que não produzam incapacidade para o trabalho, podem afetar a sobrevivência dessas mulheres durante o período de afastamento do trabalho já que, em sua maioria, não contam com os benefícios sociais de seguridade social. Portanto, não se pode inferir que acidentes entre trabalhadoras em atividades domésticas sejam apenas de pequena gravidade. No presente estudo, não se incluem as disfunções por esforços repetitivos, consideradas como resultantes de traumas crônicos, que podem ser comuns e de gravidade considerável, que serão objeto de uma outra publicação.

O emprego em atividades domésticas, além de ser a principal ocupação entre as mulheres, é também um meio freqüente de entrada de crianças e adolescentes do sexo feminino no mercado de trabalho. Isto tem sido mostrado em vários estudos sobre o trabalho infantil e de adolescentes, ${ }^{8}$ e resulta possivelmente da pouca ou nenhuma exigência de qualificação profissional formal por parte dos empregadores - famílias de praticamente todas as classes sociais - e do aprendizado "natural", no âmbito da própria família, no desempenho de atividades da rotina doméstica. Esta ocupação se assemelha a uma atividade tipicamente familiar que, em países como nos Estados Unidos ou a Europa, é exercida pelas pessoas que compartilham a mesma residência, ${ }^{1}$ o que pode explicar a escassez de dados epidemiológicos sobre essas trabalhadoras. No presente estudo, a participação de empregadas em atividades domésticas no mercado de trabalho foi de $18,3 \%$, semelhante ao estimado para o País. Nas outras ocupações, verifica-se que a participação de mulheres no mercado de trabalho passa a ser substancial por volta dos 21 anos de idade. Notou-se também que entre as empregadas em atividades domésticas prevaleciam as solteiras, um possível efeito da menor idade mas também uma provável conseqüência da dificuldade em conciliar a dedicação requerida por esta atividade com as demandas por atenção das suas próprias famílias. A baixa escolaridade e nível socioeconômico dessas mulheres refletem a conhecida falta de oportunidades de qualificação profissional e mobilidade social dos segmentos pobres dos grandes centros urbanos do Brasil, como a cidade de Salvador. Esses fatores alimentam um ciclo vicioso iniciado pela precariedade das condições de vida e limitado acesso à educação e qualificação profissional, acentuados pelo ingresso em idades muito jo- 
vens no mercado de trabalho. Esses fatores levam ao emprego precário e ao trabalho insalubre e pouco seguro, que por sua vez levam ao adoecimento ou aos acidentes de trabalho. Estes resultam no afastamento do trabalho, que com a falta de cobertura por seguro social produzem mais empobrecimento e piores condições de saúde em geral. Evidência desta falta de oportunidades pode ser encontrada na grande proporção de empregadas domésticas sem carteira assinada $(70,5 \%)$ e nas razões não pessoais para a falta de contrato legal de trabalho, uma vez que a maioria referiu "falta de oportunidade" ou "desinteresse dos patrões". O preconceito e a discriminação social dirigidos às empregadas em atividades domésticas pode ter um papel importante para os acidentes de trabalho e será foco de outra análise. Os achados do presente estudo revelam a contradição dos sentimentos dessas trabalhadoras diante da sua ocupação, uma vez que embora a maioria tenha declarado "estar satisfeita" com o trabalho, também manifestou o desejo de "trocar" de profissão, resultado já encontrado em uma outra pesquisa sobre o sofrimento psíquico em trabalhadoras com ocupação doméstica. ${ }^{16}$ Isto possivelmente é conseqüência da combinação da falta de oportunidade de trabalho em outras profissões, o que as "aprisiona" nesta ocupação, além dos efeitos sobre a subjetividade decorrentes da grande discri- minação social que demarca o serviço doméstico.

O presente estudo trata de um problema de saúde que afeta milhares de mulheres anualmente e destacase pela originalidade, posto que não foi encontrado nenhum outro estudo que trate especificamente desta temática. Todavia, deve se ressaltar que a pesquisa que lhe deu origem não foi desenhada especificamente para abordar essas trabalhadoras e que, portanto, o tamanho da população do estudo não foi definido de modo apropriado para este tema, valendo como estudo exploratório. O ajuste para o desenho da amostra, de conglomerado de superfície, não alterou significativamente os resultados. Este estudo trata de morbidade referida para o período de um ano, o que pode produzir erros de memorização, especialmente para eventos ocorridos no início do período em consideração o que levaria à subestimação dos resultados. O estudo tem o propósito de delinear a magnitude deste problema de saúde e mostrar a necessidade de ações de vigilância à saúde dessas trabalhadoras que reduzam o custo social causado pelos acidentes ocupacionais, principalmente no setor informal da economia. Além disso, considera-se a necessidade de haver estudos sobre o impacto sobre a saúde decorrente da participação de jovens no mercado de trabalho, especialmente no emprego em serviços domésticos.

\section{REFERÊNCIAS}

1. Boh K, Sgritta G, Sussman MB. Cross-cultural perspectives on families, work, and change. New York: Haworth Press; 1990.

2. Bruschini C. Gênero e trabalho no Brasil: novas conquistas ou persistência da discriminação? In: Rocha MIB da, organizadora. Trabalho e gênero: mudanças, permanências e desafios. São Paulo: Editora 34; 2000.p11-31

3. Cayless SM. Slip, trip and fall accidents: relationship to building features and use of coroners' reports in ascribing cause. Appl Ergon 2001;32:155-62.

4. Chaney EM, Castro MG. Muchachas no more: household workers in Latin America and the Caribbean. Caracas: Nueva Sociedad; 1993.

5. Conceição P, Cerqueira, MRM, Nascimento, IBO, Oliveira, PS. Acidentes de trabalho dentre os atendimentos por causas externas num serviço de emergência em Salvador, Bahia, 1999. Salvador: Abrasco; 2000. [Trabalho apresentado no VII Congresso Nacional de Saúde Pública; 2000. Salvador, BA].

6. Fachini LA, Agnol MMD, Fassa A. Trabalho e saúde infantil: projeto de investigação. Pelotas: Universidade Federal de Pelotas; 1998.
7. Fehlberg MF, Santos I, Tomasi E. Prevalência e fatores associados a acidentes de trabalho em zona rural. Rev Saúde Pública. 2001;35:269-75.

8. Fernandes MC, Mendonça LK. O trabalho da criança e do adolescente na RMS. Bahia Anál Dados 1999;4:73-88.

9. Fundação IBGE. Pesquisa Nacional por Amostragem de Domicílios. PNAD: síntese de indicadores, 1998. Rio de Janeiro: Departamento de Emprego e Rendimento; 1999.

10. Hagberg M, Christiani D, Courtney TK, Halperin W, Leamon TB, Smith TJ. Conceptual and definitional issues in occupational injury epidemiology. Am / Ind Med 1997;32:106-15.

11. Hamzaoglu O, Özkan O, Janson S. Incidence and causes of home accidents at Ankara Çigiltepe apartments in Turkey. Accid Anal Prevent 2002;34:123-8.

12. Moraes MC, Barata RC. Pesquisa sobre condições de vida: componente acidentes de trabalho e doenças profissionais. São Paulo: Fundação SEADE; 1998. 
13. Mota AB. Visão de mundo da empregada doméstica: um estudo de caso. Salvador: Departamento de Ciências Sociais da UFBA; 1977.

14. Mota AB. Emprego doméstico: revendo o novo. Cad CRH 1992;(16):31-50.

15. Ortiz IP, Joffre RL. Asi es pues: trabajadoras domesticas de Cuernavaca. Mexico: Colectivo Atabal; 1991.
16. Santana V, Almeida-Filho N. Emprego doméstico e sofrimento mental. Saúde Mental Rev 1994;2:9-8.

17. Santana V. Gestão, integração e disseminação de informações estatisticas. In: Anais do Seminário Nacional Estatísticas sobre Doenças e Acidentes de Trabalho no Brasil: situação e perspectivas; 2000 nov 6-8; S. Paulo, SP. São Paulo: Fundacentro; 2000. 